Acta Theriologica 35 (1-2): 39-51, 1990.

PL ISSN $0001-7051$

\title{
Reproductive biology of the southern African ice rat
}

\author{
Ken WILLAN
}

Willan K. 1990. Reproductive biology of the southern African ice rat. Acta theriol. 35: 39-51.

Reproduction and the postnatal development of nine litters of the southern African ice rat Otomys sloggetti robertsi Hewitt, 1927 were studied in the laboratory. Parturition and lactation occurred in the presence of up to seven cage-mates, reflecting the colonial social organization of $O$. s. robertsi. Mean litter size was 1.44 , reproductive effort 0.53 , gestation period 38 days and fecundity approximately six young p.a. Newborn young weighed $10.6-$ $-12.2 \mathrm{~g}$ and were semi-precocial. Early behaviour was dominated by nipple-clinging. Weaning occurred at 16 days old, and sexual maturity at 16 weeks in males and 11 weeks in females. Compared to $O$. s. robertsi, young of the vlei rat $O$. irroratus (Brants, 1827) are born more precocial and develop more rapidly. The microthermal environment of $O$. s. robertsi is harsh but predictable, and the subspecies is $K$-selected in terms of most reproductive parameters. Reduced fecundity and $K$-selection is further attributable to the microhabitat stabilizing effects of nesting, social huddling and food hoarding in an underground burrow.

Dept. of Biology, Univ. of Natal, King George V Avenue, Durban 4001, South Africa

Key words: reproduction, behaviour, postnatal development, Otomys sloggetti robertsi

\section{Introduction}

The ice rat Otomys sloggetti robertsi Hewitt, 1927 (Muridae: Otomyinae) is one of five subspecies of $O$. sloggetti Thomas, 1902 (Meester et al. 1986). It is the only $O$. sloggetti that has been karyotyped $(2 n=42 ;$ G. Contrafatto, unpubl.). The subspecies is endemic to the southern African Drakensberg and Maluti mountains (Roberts 1951) and is apparently restricted to the microthermal highlands of Lesotho. The name "ice rat" reflects its habit of emerging from shelter to sun itself during cold weather, particularly in winter when ice or snow are on the ground (Smithers 1983).

Access to the Lesotho highlands is difficult, and although $O$. s. robertsi is abundant in suitable habitat and is readily observed in the field, there is only fragmentary information available on the subspecies: its diet, predators and prehistory are unknown, and data on fundamental reproductive traits are lacking (De Graaff 1981, Smithers 1983).

In the course of ongoing studies on speciation in southern African otomyines (see Meester 1988) a small colony of O. s. robertsi was maintained in captivity. Breeding attempts were successful, the results of which are presented here. The ecology and socio-ecology of free-living $O$. s. robertsi are currently under investigation (K. Willan, unpubl.): in the absence of other sources of field data on this taxon, and in order to place the present laboratory study in ecological perspective, some relevant aspects of the environment and general biology of $O$. s. robertsi are outlined in section "General biology". 


\section{Materials and methods}

Eight $O$. s. robertsi (three males, five females) were livetrapped during April 1987 at Oxbow in the Malibamatso River valley, N.E. Lesotho $\left(28^{\circ} 46^{\prime} \mathrm{S}, 28^{\circ} 39^{\prime} \mathrm{E}\right.$; altitude $\left.2591 \mathrm{~m}\right) 25 \mathrm{~km}$ from the type locality of the subspecies.

The animals were housed in a room with partial environmental control: $20-23^{\circ} \mathrm{C} ; 50-70 \% \mathrm{rH}$; light regime varied to simulate seasonal shifts between summer $(15 \mathrm{~L}: 9 \mathrm{D})$ and winter $(10 \mathrm{~L}: 14 \mathrm{D})$ at $29^{\circ} \mathrm{S}$. They were initially (April-November 1987) confined together in a $1.6 \times 0.4 \times 0.4 \mathrm{~m}$ cage with two nest-boxes $15 \times 15 \times 15 \mathrm{~cm}$ at each end. Thereafter (December 1987 - June 1988) they were paired in glass aquaria $0.9 \times 0.3 \times 0.4 \mathrm{~m}$ or were kept in larger groups (up to eight animals, including progeny) in cages $1.6 \times 0.4 \times 0.4$ $\mathrm{m}$ or larger. Coarse wood shavings were provided as litter, and animals utilized uneaten plant matter as nesting material. Cages were washed and litter was replaced each week. Food comprised ad libitum coarse grass (mainly Panicum maximum), herbaceous plant material, cabbage, carrot and "Epol" rabbit pellets. Water was provided ad libitum, although the animals were never observed to drink.

Breeding took place under the conditions described above. Observations were made of adult behaviour relating to reproduction, and the size and date of birth of litters was recorded. Young were measured (standard taxonomic measurements) and weighed at 2-3 day intervals from the day of birth (day 0 ) for seven weeks, and thereafter weekly to an age of 18 weeks. Mainly to facilitate comparison with data given by Davis and Meester (1981) in respect of the postnatal development of the vlei rat $O$. irroratus (Brants, 1827), observations were made of the degree of physical development of $O$. s. robertsi at birth, the development of locomotor abilities, the timing of opening of the auditory meatus and eyes, and of weaning. Attainment of sexual maturity in males was indicated by descent of the testes into the scrotal sac and their development to full adult size, and in females by perforation of the vaginal orifice. Young were normally allowed to remain with the parents beyond sexual maturity.

The reproductive effort of females was calculated after Millar (1977) from $R_{\mathrm{e}}=N \times W_{\mathrm{w}}^{0.75} \times\left(m^{0.75}\right)^{-1}$, where $R_{\mathrm{c}}=$ reproductive effort, $N=$ litter size, $W_{\mathrm{w}}=$ mass of individual offspring at weaning, and $m=$ adult female mass.

Animals that died or were killed for electrophoretic and other procedures (see Meester 1988) were prepared as study specimens and will be lodged in the mammal collections of the Durban Museum.

\section{General Biology \\ Morphology}

Adult $O$. s. robertsi weigh $120-140 \mathrm{~g}$ and have the following linear measurements: head-body $150-170 \mathrm{~mm}$, tail $60-70 \mathrm{~mm}$, hind foot (s.u.) $24-26 \mathrm{~mm}$, ear 16-17 mm and greatest skull length 38.5-40 $\mathrm{mm}$ (Roberts 1951, K. Willan, unpubl.). Males are some $10 \%$ larger than females in respect of all linear measurements. The pelage is reddish-brown with rusty-yellow at the sides of the snout and behind the ear pinnae, and is soft, fine and thick. The kidney of $O$. s. robertsi has a low medulla/cortex ratio $(\overline{\mathrm{x}}=1.40)$ and other features indicating mesic physiological adaptation (Pillay et al., in print).

\section{Environment}

O. s. robertsi does not occur at altitudes below approximately $2,500 \mathrm{~m}$ and De Graaff (1981) is incorrect in stating that the ice rat occurs at altitudes of up to $1,800 \mathrm{~m}$. The type locality of the subspecies (Mont-aux-Sources near the South Africa/Lesotho border) is at 3,282 $\mathrm{m}$ (Roberts 1951).

The Drakensberg/Maluti massif comprises an ancient basaltic plateau bisected by 
deep, steeply sloping valleys which may fall to $500 \mathrm{~m}$ or more below adjacent highlands. The plateau undulates gently, and extensive bogs formed as a result of water seepage to lower ground are common. Soil depth is inversely related to gradient. O. s. robertsi is widespread at suitable altitude, although populations tend to be localized, occurring on level or gently sloping ground with abundant surface and/or subsurface rock; it is absent from boggy areas, steep slopes and deep valleys. Its habitats appear invariably to receive continuous insolation from sunrise to sunset, and aspect may thus be a critical determinant of habitat suitability.

The climate of the Lesotho highlands is characterized by a low temperature profile and high rainfall; the growing season is short and primary productivity low (Killick 1978). The locality from which $O$. s. robertsi was obtained for the present study (Oxbow) experiences a mean temperature of $1.8^{\circ} \mathrm{C}$ in June and $12.2^{\circ} \mathrm{C}$ in January; absolute minimum temperature is $-13.1^{\circ} \mathrm{C}$ and absolute maximum $21.6^{\circ} \mathrm{C}$; snow may fall during any month but occurs mainly during May-September; mean annual rainfall is $1,277 \mathrm{~mm}$, occurring mainly during October-March (Killick 1978). The climate becomes more severe with increasing altitude: at Letseng-la-Draai $(3,050 \mathrm{~m})$ on the Drakensberg/Maluti summit plateau, sub-zero night temperatures occur even in summer, the estimated number of frost days is 183 p.a. and absolute minimum temperature is $-20.4^{\circ} \mathrm{C}$ (Killick 1978). In the sense of Pianka (1970) and subsequent students of life history evolution, the climate within the distributional range of $O$. $s$. robertsi is predictably harsh.

O. s. robertsi is confined to the subalpine $(1,830-2,895 \mathrm{~m})$ and alpine $(2,860-$ $-3,484 \mathrm{~m}$ ) phytogeographic belts, as defined by Killick (1978). The Lesotho highlands are included within the sparse Themeda-Festuca alpine veld of Acocks (1988; vegetation type 58) but the main plant community of the plateau is Erica-Helichrysum alpine heath (Killick 1978); trees and other large woody plants are absent from the highlands.

The non-fossorial small mammal community at Oxbow comprises, in addition to $O$. s. robertsi, small populations of $O$. irroratus, the striped mouse Rhabdomys pumilio and the forest shrew Myosorex varius. These species are more or less at the limit of their high-altitude range at Oxbow, and $O$. s. robertsi appears to be the only non-fossorial small mammal present on the summit plateau.

Few potential predators on $O$. s. robertsi are known from the Lesotho highlands (snakes-FitzSimons 1962; raptors-Maclean 1985; small mammalian carnivores-De Graaff 1981, Smithers 1983), and I have observed none during field work in Lesotho. Predator populations are at best low, possibly due to a shortage of rodent prey, especially on the summit plateau. In addition, predators may have been locally extirpated as a result of sustained hunting by indigenous Basotho herdsmen.

\section{Ecology and social organization}

$O$. s. robertsi is strictly diurnal. Above-ground activity is strongly influenced by temperature; activity is limited to the few warmest hours of the day during cold 
weather, and animals may not be seen for several days during prolonged periods of intense cold. Basking frequencies are highest during early morning and late afternoon.

The shallow $(300-400 \mathrm{~mm})$ underground burrow system includes at least two entrance tunnels and several interconnected chambers invariably sited beneath surface or subsurface rock. Crevices in the rock foundations of roads and bridle paths artificially increase the availability of nest sites. Population densities of $O$. s. robertsi tend to be higher at such localities than in adjoining areas of undisturbed habitat, suggesting that domiciles may be a limiting resource.

Like all otomyines for which information on feeding habits exists (De Graaff 1981, Smithers 1983) O. s. robertsi is a specialist herbivore, feeding on the stems, leaves and floral parts of a wide range of green plants. Large quantities of food were present in burrows excavated in the field, and hoarding behaviour is typical in the laboratory. Climatic limitations on above-ground activity have no doubt selected for hoarding.

Breeding occurs during October-March. Population densities peak in autumn, and are highly variable from year to year. O. s. robertsi appears to be resource-limited, at least at high population densities, and experiences mainly density-dependent mortality.

No nipple-clinging or small weaned $O$. s. robertsi have been observed in the field. The smallest animal caught at Oxbow and elsewhere in Lesotho weighed $56 \mathrm{~g}$, and was approximately five weeks old (see "Postnatal development"). The gestation period of O. s. robertsi is approximately 38 days (see "Reproduction in captivity"), and above-ground emergence of young (and, presumably, independent feeding activity) therefore more or less coincides with the birth of the next litter in multiparous females.

$O$. s. robertsi may occur at densities of 100 or more animals/hectare during times of high population density. The subspecies is colonial and the pattern of dispersion is typically clumped, each colony occupying several discrete burrow systems situated in close proximity to one another. Agonistic interaction is rare among free-living members of a particular colony, and up to six animals have been observed occupying a single burrow system. Interaction between members of different colonies has not been observed.

\section{Breeding behaviour}

Adult interaction

Two patterns emerged during attempts to establish breeding pairs and larger groups of $O$. s. robertsi. First, irrespective of their age and sex, animals which were not in reproductive condition when they met in the laboratory displayed little aggression toward one another; amicable interaction predominated immediately or within a few days of introduction, with two or more animals sharing a single nest-box. Second, intense agonism and damaging fights invariably resulted when sexually active animals were introduced. Animals were potentially intersexually aggressive, and a female and two males died as a result of wounding by cage-mates of the opposite sex. 
Except in one case, young that were allowed to remain with the parents beyond adulthood $(n=7)$ did not breed and were tolerated by the parents. The exception was a young female which was mated by the father and was attacked and severely injured during late pregnancy by the mother. Similarly, reproductive activity in larger founding groups $(\mathrm{n}=3)$ was limited to a single pair. The mechanisms of dominance and reproductive inhibition of subordinate animals were not ascertained.

Courtship, mating and parturition were not observed. Predictably (in view of the diurnal above-ground activity of $O$. s. robertsi), parturition occurred at night: new litters were present when nest-boxes were checked soon after the beginning of the artificial day. Pregnant and lactating females did not exclude their own weaned young or other occupants of the cage from the nest, even during the day before or following the birth of a litter.

\section{Care of the young}

Young $O$. s. robertsi clung to the mother's nipples continuously during the first 2 - 3 days after birth, during which time the mother did not leave the nest-box. The incidence of nipple-clinging declined gradually to weaning, although young were occasionally observed attached to the mother's nipples for up to two weeks after weaning (see "Postnatal development").

Young $O$. s. robertsi were cared for entirely by the mother, and were ignored by other animals. Neonates that were returned to the cage following examination were allowed to attach to the mother's nipples and dragged back to the nest. Mouth-carrying was not observed.

Pregnant and lactating females were not aggressive toward the observer. While they attempted to escape from the nest-box when the lid was removed, they did not bite during handling, or aggressively defend the young.

\section{Reproduction in captivity}

Nine litters totalling 13 young were born from five matings (Table 1). Mean litter size was $1.44(\mathrm{SE}=0.17)$ and the male/female sex ratio $5: 8\left(\chi^{2}=0.69 ; p>0.30\right)$. Primiparous females (i.e. females 1 and 3 , which were subadult at the time of capture, and females 2 and 4, which were bred in captivity; Table 1) each produced a first litter of one. Female 5 weighed $102 \mathrm{~g}$ when captured in April 1987 and may have been repreductively active prior to capture. The size of the second litter increased to two in those females which produced more than one litter, then declined to one young in the last litter produced by female 1 (Table 1). This female lost weight and physical condition during her last lactation (January 1988), maintained an oestrus thereafter, and died during July 1988. Autopsy revealed no pathological cause of death.

The 38 day minimum interval between litters (Table 1) is taken to approximate the gestation period of $O$. s. robertsi. The mean interval between successive litters born to individual females was 49.0 days $(\mathrm{SE}=8.4)$. Excluding one 74 day inter-litter interval 
Table 1. Reproductive capacity of $O$. s. robertsi.

\begin{tabular}{cclccc}
\hline Female No. & $\begin{array}{c}\text { Litters per } \\
\text { female }\end{array}$ & $\begin{array}{c}\text { Young per } \\
\text { litter }\end{array}$ & \multicolumn{2}{c}{ Number of } & Inter-litter \\
& 4 & $1,2,2,1$ & 2 & 4 & $74,43,38$ \\
1 & 2 & 1,2 & 1 & 2 & 41 \\
2 & 2 & 1 & & 1 & \\
3 & 1 & 1 & 1 & & \\
4 & 1 & 2 & 1 & 1 & \\
5 & 1 & 2 & & &
\end{tabular}

(Table 1), which apparently represented a period of sustained an oestrus, mean interval between successive litters was 40.7 days $(\mathrm{SE}=1.4)$, suggesting that mating usually occurs during the first postpartum oestrus.

Reproductive effort of $O$. s. robertsi was 0.53 , calculated from a mean postpartum female mass of $111.4 \mathrm{~g}(\mathrm{n}=9)$, a mean mass of young at weaning of $29.2 \mathrm{~g}$ $(\mathrm{n}=10)$, and a mean litter size of $1.44(\mathrm{n}=9)$.

\section{Postnatal development}

The young of $O$. s. robertsi were born semi-precocial. They were well furred dorsally, with the pelage $1-2 \mathrm{~mm}$ in length and paler (i.e. dark buffy, with rusty-yellow behind the ears) than the red-brown colouration of adults, but the ventral parts were naked and unpigmented. Vibrissae up to $10 \mathrm{~mm}$ long were present. The eyes were sealed, although incipient eye-slits were visible. The ear pinnae were unfolded and slightly fleshy. The auditory meatus was closed and there was no response to sound. The toes were unfused, and claws approximately $1 \mathrm{~mm}$ long were present. Both the upper and lower incisors were erupted, the upper protruding approximately $0.5 \mathrm{~mm}$ and the lower barely visible. Inspection of the cleaned skull of an individual which died soon after birth (day 0 ) showed that the upper and lower cheek teeth protruded $0.5 \mathrm{~mm}$ above the sockets, but it is not known whether they protruded beyond the gums. Locomotor abilities were poorly developed: young were unable to crawl on a flat surface or to right themselves when placed on their back.

The auditory meatus opened at 2-3 days old and the first response to sound was noted two days later. The eyes began to open at $10-11$ days, and were fully open by day $13-14$. Feeding on solids was first observed on day 12 , and weaning was complete by day 16 when it was no longer possible to express milk from the mother's nipples and lactation had apparently ceased. Feeble crawling and righting were possible by day 2 , but fully co-ordinated walking and running did not occur until day 10-12.

Figure 1 illustrates the increase in linear measurements and mass of young from birth to 18 weeks, the age at first mating. Age-specific variation of linear measurements (but not of mass; below) was slight between individuals, with $\mathrm{SE}<4 \%$ of the mean for all ages/measurements. Hind foot length most rapidly attained $95 \%$ of mean adult size, followed by ear, tail and head-body length.

Young weighed $10.6-12.2 \mathrm{~g}$ at birth, and there was little inter-individual variation 


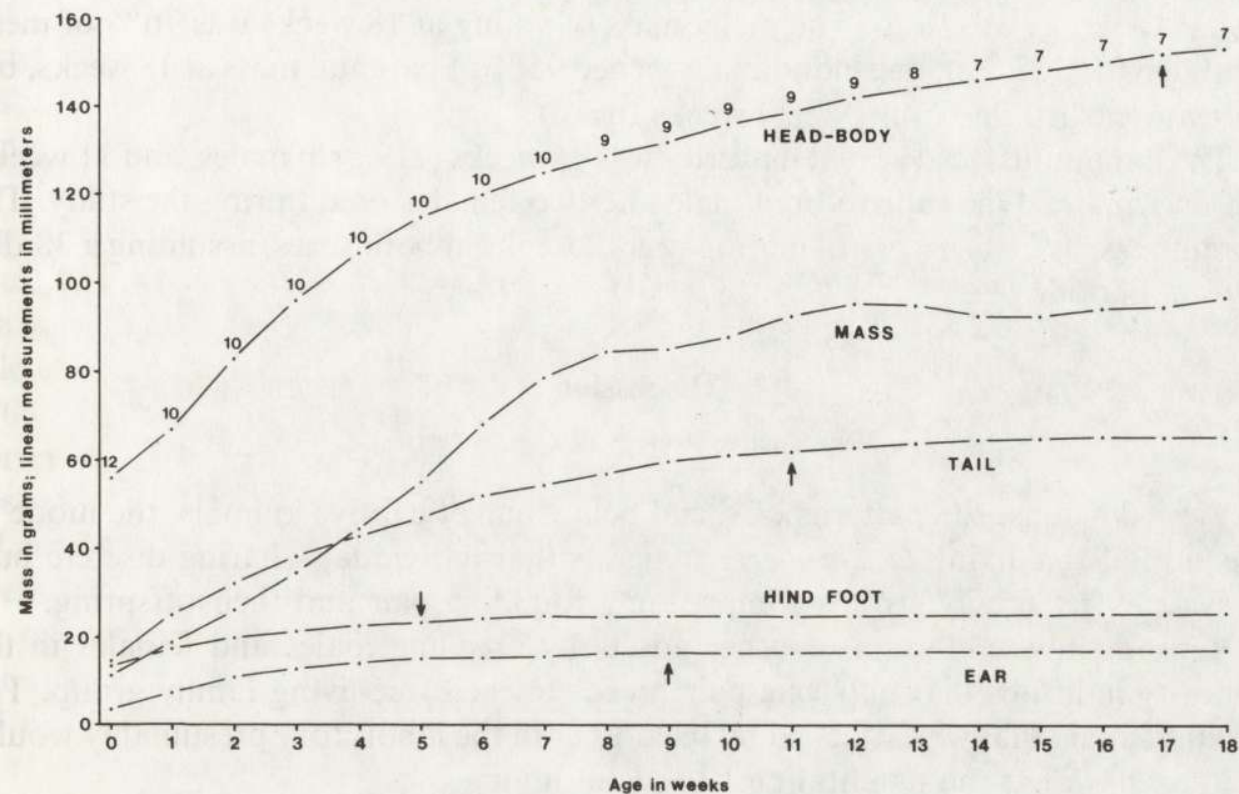

Fig. 1. Physical growth of $O$. s. robertsi from birth to 18 weeks of age. Sample size indicated in the body of the figure. Arrows indicate $95 \%$ of mean adult measurements.

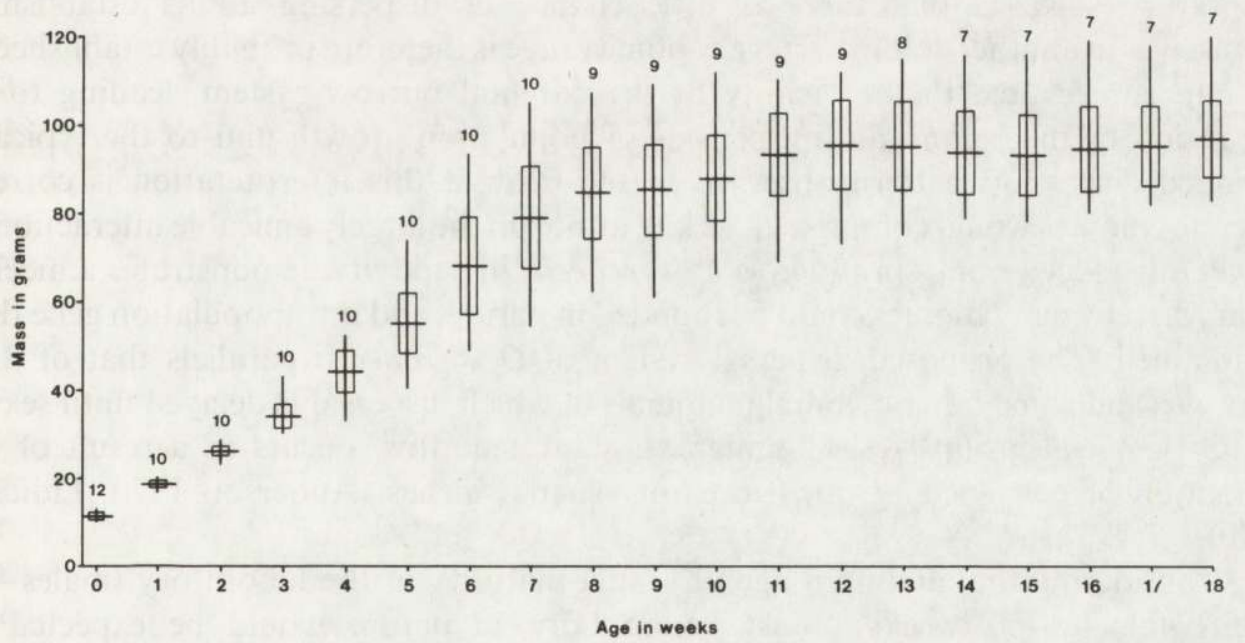

Fig. 2. Mass increase of $O$. s. robertsi from birth to 18 weeks of age. Total sample variation indicated by vertical lines, the mean by horizontal lines, and two standard errors of the mean by enclosed rectangles. Sample size indicated in the body of the figure.

in rates of mass increase to weaning (Fig. 2). Thereafter, some young grew more rapidly than others: individual variation in age-specific mass reached a maximum at seven weeks when the mass of the smallest animal was only $51 \%$ of the largest; the equivalent 
value at 18 weeks was $71 \%$. The mean mass of young at 18 weeks was $76 \%$ of mean parental mass $(127.2 \mathrm{~g})$; one individual reached $95 \%$ of parental mass at 18 weeks, but the mean reached $95 \%$ only at 30 weeks $(n=6)$.

The minimum age at sexual maturity was 16 weeks $(119 \mathrm{~g})$ in males, and 11 weeks $(90 \mathrm{~g})$ in females. One captive-bred male and two females bred during the study. The minimum age at first successful mating was 18 weeks in both sexes, assuming a 38-day gestation period.

\section{Discussion \\ Reproductive strategy of $O$. s. robertsi}

Viewed against the patterns of social behaviour of captive animals, the mode of dispersion of free-living $O$. s. robertsi suggests that individuals sharing discrete burrow systems are family groups comprising a founding pair and their offspring.

Reproductive inhibition of other adults by breeding males and females in the laboratory indicates that only one pair breeds in each free-living family group. The pregnant female that was attacked by its mother in the laboratory presumably would, in nature, have left the parental nest to avoid injury.

Dispersal in $O$. s. robertsi may normally occur only at sexual maturity. The intense, direct agonism displayed by sexually active animals when introduced in the laboratory suggests that there is little chance of dispersing adults establishing themselves in another colony. The new home range is therefore probably established in an unoccupied area in the vicinity of the parental burrow system, leading to an expansion of the colony during periods of population growth and to the typically clumped dispersion pattern observed in the field. If this interpretation is correct, discrete colonies would comprise close kin, although the largely amicable interaction of newly introduced non-reproductive $O$. s. robertsi in captivity demonstrates a mechanism whereby new colonies could be founded in nature, and intrapopulation gene flow maintained. The proposed dispersal system of $O$. s. robertsi parallels that of Mus musculus and some other colonial mammals in which dispersal is delayed until sexual maturity, social groups resist immigrants, and gene flow occurs as a result of the formation of new social groups in empty spatial niches (Anderson 1970, Lidicker 1976).

Considering the minimum age at sexual maturity in the laboratory (males - 16 weeks; females-11 weeks), most young born in nature would be expected to overwinter with the parental group, and to attain sexual maturity and disperse in spring. Social huddling with parents and siblings during overwintering would clearly convey energetic advantages to subadults.

The reproductive life expectancy of female $O$. s. robertsi may be a single season. This tentative conclusion is based on limited data from a single female (female 1; Table 1) which was captured as a $66 \mathrm{~g}$ subadult in April 1987, produced four litters during the period September 1987-February 1988, did not breed thereafter, and died during 
winter 1988 despite constant availability of high quality food. This female produced six young during the artificial breeding season, which may approximate the maximum seasonal (and perhaps lifetime) reproductive output of $O$. s. robertsi. High survival of young would compensate for the low fecundity of the subspecies.

Despite its simple dualism (Stearns 1976), the theory of $r$ - and $K$-selection (MacArthur and Wilson 1967), as developed by Pianka (1970) and subsequent authors, is robust and offers the most credible explanation of life history phenomena (i. a. Stearns 1977, Boyce 1984, Zammuto and Millar 1985). Species occurring in unpredictable and predictable environments tend to be $r$ - and $K$-selected respectively (Pianka 1970). While the breeding season and reproductive longevity of $O$. s. robertsi are shorter than would be predicted in optimally $K$-selected species (Pianka 1970), the subspecies has the following $K$-selected reproductive attributes: long gestation period and generation time, small litter size, low reproductive effort and fecundity, and well developed parental care. It is therefore clear that $O$. s. robertsi is essentially $K$-selected, reflecting the comparative predictability of the Lesotho highlands climate and, probably, the microhabitat stabilizing effects of subsurface nesting, social huddling and hoarding.

\section{Significance of nipple-clinging}

Nipple-clinging has previously been reported in several otomyine species including O. irroratus (Davis and Meester 1981), and is probably characteristic of all otomyines, as indicated by the presence of only two pairs of inguinal mammae in members of the subfamily (Roberts 1951). Nipple-clinging is thought to enhance survival of young rodents by reducing their vulnerability to predation (i. a. King 1963). This view is widely supported in the context of otomyine (Dieterlen 1968, Davis 1972, Davis and Meester 1981, Brown 1988, Willan and Meester 1989) and other African rodents (Meester and Hallett 1970, Brooks 1972, Panagis and Nel 1981). Nipple-clinging by $O$. s. robertsi young beyond weaning endorses this conclusion.

Palaeontological (Pocock 1976) and biochemical evidence (Taylor et al. 1989) indicates that the subfamily Otomyinae is divided into two distinct evolutionary lineages derived from a Pliocene ancestor, Prototomys. One lineage includes $O$. irroratus, and the other $O$. sloggetti and the bush Karoo rat $O$. unisulcatus. On mainly palaeoclimatic grounds, Taylor et al. (1989) hypothesize that Prototomys was mesically adapted. This hypothesis is supported by consideration of the nesting habits and consequent vulnerability to predation of young $O$. irroratus, $O$. s. robertsi and $O$. unisulcatus. O. irroratus is a mesophylic species (Perrin 1981, Willan and Hickman 1986) occupying densely vegetated habitats and generally nesting on the surface beneath overhanging vegetation (Davis 1973); the high risk of predation on the young selects for nipple-clinging (Davis and Meester 1981). The arid-adapted $O$. unisulcatus nests in a twig "lodge" (Vermeulen and Nel 1988) which is an effective deterrent to predators (Brown 1988). The risk of predation on young $O$. s. robertsi is probably insignificant, as indicated by its nesting habits, delayed emergence of young from the 
burrow and the low incidence of predators in its habitats. It is unlikely that selection for nipple-clinging would have occurred in an ancestral otomyine in which the nest was adequately protected against predators, and it seems probable that, like $O$. irroratus, Prototomys was adapted to high cover density, nested on the surface and had nipple-clinging young. $O$. irroratus therefore appears ecologically analogous to Prototomys. Nipple-clinging in $O$. s. robertsi and $O$. unisulcatus may represent a plesiomorphic otomyine character with little or no adaptive significance.

\section{Significance of hoarding}

Hoarding may be primarily an adaptation to survive periods of intense cold but, due to the generally cool and often cold conditions that prevail even during the breeding season of $O$. s. robertsi, is reproductively significant. Restriction of lactating females to the nest during the first few days after parturition, and of young until first above-ground activity at about five weeks old, is directly attributable to the availability of food stored in the burrow. Nest-restriction of the mother after parturition permits ad libitum suckling and would increase the safety of her offspring. While the thermoregulatory abilities of the young are probably fully developed sooner than five weeks old, their high surface/volume ratio would be energetically disadvantageous under cold conditions. Delayed emergence from the burrow may therefore enhance the survival of young. This factor, together with the protection afforded by the burrow and mother, may have selected for a reduction in the litter size of $O$. s. robertsi relative to $O$. irroratus (see below).

Hoarding also has socio-ecological implications. Breeding in $O$. s. robertsi is co-operative in that food hoarded by members of the group other than the mother is potentially utilized by the reproductive female during early lactation, and by her weaned young until emergence from the burrow.

\section{Comparison with $O$. irroratus}

There is little more than anecdotal information available on reproduction in most Otomys species, but there have been several relevant studies on $O$. irroratus, permitting meaningful comparison with data on $O$. s. robertsi. Data from Perrin $(1980,1986)$ are not considered here, on the grounds that the population he studied is distinct from "typical" mesophilic $O$. irroratus in terms of important environmental (Willan and Meester 1989), cytogenetic (G. Contrafatto, unpubl.) and electrophoretic (P. Taylor, unpubl.) parameters.

Except at the upper limit of its altitudinal range, for example at Oxbow, $O$. irroratus occurs at lower, warmer altitudes than O. s. robertsi (Roberts 1951). The carrying capacity of the mesic habitats of $O$. irroratus is perennially high and stable, and the species is $K$-selected (Willan and Meester 1989). The complex social organization includes multiple home range overlap and temporal territoriality (Davis 1972) as defined by Leyhausen (1965), intrasexual defence of a small area around the nest by breeding females, and hierarchical relationships among breeding males (Davis 
1973).

Unlike O. s. robertsi, aggression in O. irroratus is ritualized (Willan 1982) and damaging fights between males and females, including animals in reproductive condition paired for breeding ( $\mathrm{n}>30 ; \mathrm{K}$. Willan, unpubl.), are rare. This difference reflects the social organizational and dispersal adaptations of the two taxa. $O$. $s$. robertsi probably mainly employs direct aggression to repel members of other colonies (which are unlikely to be close kin). In contrast, ritualization of aggression in the territorial $O$. irroratus may be largely due to the short dispersal distance of the young (11-12 m; Davis 1973, Brown 1987): competitors which meet in nature are therefore potentially close kin between which damaging conflict is avoided.

The earliest sexual maturity in $O$. irroratus males and females occurs at eight and four weeks old respectively; earliest lactation is at 13 weeks old (Davis and Meester 1981). It is therefore evident that reproductive activity is delayed in $O$. $s$. robertsi relative to $O$. irroratus, possibly reflecting the shorter growing season in the cold Lesotho highlands relative to the lower altitude habitats of $O$. irroratus. Similarly, Barash (1974) explained variation in the age at sexual maturity of three Marmota spp. in terms of temperature gradients: the Olympic marmot $M$. olympus occurs in cold, high altitude habitats where the growing season is short, and delays sexual maturity relative to lower altitude species.

The higher litter size (2.33), reproductive effort $(0.74)$ and fecundity ( $9-12$ young

Table 2. Mean mass and linear measurements of newborn $O$. s. robertsi and $O$. irroratus expressed as percentages of mean adult values. $(O$. irroratus data from Davis and Meester 1981).

\begin{tabular}{lcccccc}
\hline \multirow{2}{*}{ Taxon } & \multirow{2}{*}{ n } & Mass & \multicolumn{4}{c}{ Linear measurements } \\
\cline { 3 - 7 } & & & $\begin{array}{c}\text { Head- } \\
\text { body }\end{array}$ & Tail & $\begin{array}{c}\text { Hind } \\
\text { foot }\end{array}$ & Ear \\
\hline O. s. robertsi & 12 & 8.9 & 35.5 & 21.6 & 53.1 & 21.0 \\
O. irroratus & 28 & 8.7 & 44.1 & 33.8 & 61.8 & 40.8 \\
\hline
\end{tabular}

p.a.) of $O$. irroratus (Davis and Meester1981) relative to $O$. s. robertsi may be mainly explained by the comparatively high risk of predation on O. irroratus (Davis 1973), and suggests that parental care of the young is more efficient in $O$. s. robertsi.

The condition at birth of $O$. s. robertsi and $O$. irroratus (Davis and Meester 1981) apparently demonstrates divergent adaptation within the constraints of precociality of the newborn young. Expressed as a percentage of mean adult values, the mass of newborn $O$. irroratus and $O$. s. robertsi is similar, but all linear measurements are greater in $O$. irroratus (Table 2). In contrast to $O$. s. robertsi, newborn $O$. irroratus have the ventral surface furred, the ear pinnae fully expanded, and the auditory meatus open, while some individuals have the eyes open at birth. The early postnatal development of $O$. irroratus is also more rapid in many respects, with the eyes of most young opening at two days old and weaning complete by 13 days. $O$. irroratus young have the righting 
response present at birth, and co-ordinated running is possible by day five.

It is apparent that $O$. irroratus young are more fully precocial than $O$. s. robertsi, which may be partially explained by the shorter gestation period of $O$. s. robertsi ( 38 days) relative to $O$. irroratus (40 days; Davis and Meester 1981). It is possible, in addition, that low temperatures and poorer food quality in the habitats of $O$. s. robertsi may negatively influence foetal growth. Increased precociality in $O$. irroratus relative to $O$. s. robertsi is apparently an adaptation to surface nesting and the associated risk of predation on the young.

The reduced length of the head-body and extremities (tail, hindfoot and ear) of young $O$. s. robertsi relative to $O$. irroratus (Table 2 ) confers a lower surface/volume ratio on developing $O$. s. robertsi. This condition is no doubt favourable in the microthermal environment of $O$. s. robertsi, with reinforcement for a reduced surface/volume ratio resulting from the nesting and hoarding habits of the subspecies. No advantage in this regard would accrue to the surface-nesting $O$. irroratus in its warmer habitats.

Acknowledgements: My thanks to the following: A. Grace, S. Shezi and P. Wright for technical assistance; J. Meester and N. Pillay for commenting on the manuscript; and the University of Natal Research Fund for financial support.

\section{References}

Acocks J. P. H. 1988. Veld types of South Africa, 3rd Ed. Mem. Bot. Surv. S. Afr. 40: 1-146.

Anderson P. K. 1970. Ecological structure and gene flow in small mammals. Symp. Zool. Soc., Lond. 26: $299-325$.

Barash D. P. 1974. The evolution of marmot societies: a general theory. Science 185: 415-420.

Boyce M. S. 1984. Restitution of $r$-and $K$-selection. Oecologia 4: 260-264.

Brooks P. M. 1972. Postnatal development of the African bush rat Aethomys chrysophilus. Zool. Afr. 7: $85-102$.

Brown E. D. 1988. Comparative socio-ecology of Otomys irroratus and Otomys unisulcatus. M.Sc thesis, Univ. of Fort Hare: 1-184.

Davis R. M. 1972. Behaviour of the vlei rat, Otomys irroratus (Brants, 1827). Zool. Afr. 7: 119-140.

Davis R. M. 1973. The ecology and life history of the vlei rat, Otomys irroratus (Brants, 1827), on the Van Riebeeck Nature Reserve, Pretoria. D. Sc. thesis, Univ. of Pretoria: 1-171.

Davis R. M. and Meester J. 1981. Reproduction and postnatal development in the vlei rat, Otomys irroratus, on the Van Riebeeck Nature Reserve, Pretoria. Mammalia 45: 99-116.

De Graaff G. 1981. The rodents of southern Africa. Butterworths, Durban: 1-267.

Dieterlen F. 1968. Zur Kenntnis der Gattung Otomys (Otomyinae; Muridae; Rodentia). Beiträge zur Sytematik, Ökologie und Biologie Zentralafrikanischer Formen. Z. Säugetierk. 33: 321-352.

FitzSimons V. F. M. 1962. Snakes of southern Africa. Purnell, Cape Town: 1-423.

Killick D. J. B. 1978. The Afro-alpine region. [In: Biogeography and ecology of southern Africa. M. J. A. Werger, ed.] Junk, The Hague: 515-560.

King J. A. 1963. Maternal behaviour in Peromyscus. [In: Maternal behaviour in mammals. H. L. Rheingold, ed.]. Wiley, New York: 58-93.

Leyhausen P. 1965. The communal organization of solitary animals. Symp. Zool. Soc., Lond. 14: 249-263.

Lidicker W. Z. 1976. Social behaviour and density regulation in house mice living in large enclosures. J. 
Anim. Ecol. 45: 677-697.

MacArthur R. H. and Wilson E. O. 1967. The theory of island biogeography. Princeton Univ. Press, Princeton: 1-203.

Maclean G. L. 1985. Robert's birds of southern Africa. John Voelcker Bird Book Fund, Cape Town: 1-848.

Meester J. 1988. Chromosomal speciation in southern African small mammals. S. Afr. J. Sci. 84: 721 - 724

Meester J. and Hallett A. F. 1970. Notes on early postnatal development in certain Southern African Muridae and Cricetidae. J. Mammal. 51: 703-711.

Meester J., Rautenbach I. L., Dippenaar N. J. and Baker C. M. 1986. Classification of southern African mammals. Transvaal Mus. Monogr. 5: 1-359.

Millar J. S. 1977. Adaptive features of mammalian reproduction. Evolution 31: 370-386.

Panagis K. and Nel J. A. J. 1981. Growth and behavioural development in Thamnomys dolichurus. Acta theriol. 26: $381-392$.

Perrin M. R. 1980. The breeding strategies of two coexisting rodents, Rhabdomys pumilio and Otomys irroratus: with a brief review of some pertinent life history ideas. Acta Oecol. 1: $383-410$.

Perrin M. R. 1981. Notes on the activity patterns of 12 species of southern African rodents and a new design of activity monitor. S. Afr. J. Zool. 16: 248-258.

Perrin M. R. 1986. Some perspectives on the reproductive tactics of southern African rodents. Cimbebasia (A) 8: 63-77.

Pianka E. R. 1970. On $r$-and $K$-selection. Amer. Nat. 104: $592-597$.

Pillay N., Willan K. and Taylor P. J. (in print). Comparative renal morphology of some southern African otomyine rodents. S. Afr. J. Zool.

Pocock T. N. 1976. Pliocene mammalian microfauna from Langebaanweg: a new fossil genus linking the Otomyinae with the Murinae. S. Afr. J. Sci. 72: 58-60.

Roberts A. 1951. The mammals of South Africa. Mammals of South Africa Book Fund, Johannesburg: $1-701$.

Smithers R. H. N. 1983. The mammals of the southern African subregion. Univ. of Pretoria, Pretoria: $1-736$.

Stearns S. C. 1976. Life-history tactics: a review of the ideas. Q. Rev. Biol. 51: 3-47.

Stearns S. C. 1977. The evolution of life history traits: a critique of the theory and a review of data. Ann. Rev. Ecol. Syst. 8: 145-172.

Taylor P. J., Campbell G. K., Meester J., Willan K. and van Dyk D. 1989. Genetic variation in the African rodent subfamily Otomyinae (Muridae). 1. Allozyme divergence among four species. S. Afr. J. Sci. 85: $257-262$.

Vermeulen H. C. and Nel J. A. J. 1988. The bush Karoo rat Otomys unisulcatus on the Cape West Coast. S. Afr. J. Zool. 23: 103-111.

Willan K. 1982. Social ecology of Otomys irroratus, Rhabdomys pumilio and Praomys natalensis. $\mathrm{Ph} . \mathrm{D}$ thesis, Univ. of Natal: 1-294.

Willan K. and Hickman G. C. 1986. Some responses of Otomys irroratus, Mastomys natalensis and Rhabdomys pumilio (Rodentia: Cricetidae, Muridae) to food deprivation. Cimbebasia (A) 8: 147-153.

Willan K. and Meester J. 1989. Life history tactics of southern African Mastomys natalensis, Otomys irroratus and Rhabdomys pumilio (Mammalia, Rodentia). [In: Alternative life history styles of animals. M. N. Bruton, ed.]. Kluwer, Dordrecht: 421-439.

Zammuto R. M. and Millar R. S. 1985. Environmental predictability, variability, and Spermophilu. columbianus life history over an elevational gradient. Ecology 66: 1784-1794.

Received 24 August 1989, accepted 11 October 1989. 